\title{
Consumption of sweet foods and mammographic breast density: a cross-sectional study
}

\author{
Caroline S Duchaine ${ }^{1,2}$, Isabelle Dumas ${ }^{2}$ and Caroline Diorio ${ }^{1,2,3^{*}}$
}

\begin{abstract}
Background: The increasing consumption of sugar worldwide seems to lead to several health problems, including some types of cancer. While some studies reported a positive association between sweet foods intake and breast cancer risk, little is known about their relation to mammographic density (MD), a strong breast cancer risk factor. This study examined the association of sweet foods and drinks intake with MD among 776 premenopausal and 779 postmenopausal women recruited at mammography.

Methods: A food-frequency questionnaire was used to assess intake of sweet foods, sugar-sweetened beverages and spoonsful of sugar added. Percent and absolute breast density were estimated using a computer-assisted method. Multivariate generalized linear models were used to evaluate associations. All models were adjusted for potential confounders, including age and body mass index.

Results: For increasing quartiles of sugar-sweetened beverages intake, adjusted-mean absolute density was respectively $32,34,32$ and $36 \mathrm{~cm}^{2}$ among all women $\left(P_{\text {trend }}=0.040\right)$ and $43,46,44$ and $51 \mathrm{~cm}^{2}$ among premenopausal women $\left(P_{\text {trend }}=0.007\right)$. For increasing quartiles of sweet foods intake, adjusted-mean percent density was respectively $16,16,17$ and $19 \%$ among postmenopausal women $\left(P_{\text {trend }}=0.036\right)$. No association was shown between intake of spoonsful of sugar added and MD.
\end{abstract}

Conclusion: Our results suggest that an increase in sweet foods or sugar-sweetened beverage intake is associated with higher MD.

Keywords: Epidemiological, Breast density, Sugar intake, Breast cancer, Diet

\section{Background}

It has been recently suggested that consumption of foods high in added sugar is the source of many of the greatest health problems in the world today [1]. Sugar consumption has tripled over the past 50 years and the World Health Organization (WHO), in collaboration with the FAO (Food and Agriculture Organization of the United Nations), has published some recommendations to reduce this consumption worldwide [2]. In fact, excessive sugar intake seems to lead to human health problems like the ones associated with metabolic syndrome $[2,3]$ and several types of cancer, including breast

\footnotetext{
* Correspondence: caroline.diorio@uresp.ulaval.ca

'Département de médecine sociale et préventive, Centre de recherche sur le cancer, Université Laval, 2325, rue de I'Université, G1V OA6 Quebec City, QC, Canada

${ }^{2}$ Axe Oncologie, Centre de recherche du CHU de Québec, Hôpital du Saint-Sacrement, 1050, chemin Ste-Foy, G1S 4 L8 Quebec City, QC, Canada Full list of author information is available at the end of the article
}

cancer [4-6]. At a cellular level, it has been shown that sugar would enhance cellular proliferation and migration, induce DNA damage and increase inflammation $[7,8]$. All of these adverse effects are related to cancer pathogenesis.

Several studies [4,9-20], although not all [21-29], have found a positive association between sweet foods/drinks and breast cancer risk among premenopausal women $[14,16,20]$, postmenopausal women $[16,20]$ or both combined $[4,9-13,15,17-20]$. In all of the studies that found a positive association, the frequencies of consumption of several sweet foods or drinks were summed into one $[9,11,12,14-19]$ or two $[4,10,13,20]$ groups. In contrast, among the studies that showed no association, most of them have examined some sweet foods and drinks separately [21,23-25,27-29]. These results may suggest that the sum of sweet items consumed would be associated with breast cancer risk rather than a specific sweet food 
item intake, therefore it would be the amount of sweet items intake that has an effect, and not a specific food.

Mammographic density (MD) is a well-established breast cancer risk factor and it appears to act as an intermediate marker [30-32]. Considering that elevated MD may reflect an increase in the proliferation of fibroglandular breast cells [33], it is likely that a high intake of sweet foods and sugar-sweetened beverages may lead to an increase in MD. Up to now, two studies conducted among pre- and postmenopausal women have evaluated the association between consumption of sweet items and MD [34,35]. Voon et al. observed a positive association between intake of sweet foods and MD [34], while Masala et al. found a non-significant positive association between intake of spoonsful of sugar added and MD [35].

The present study aimed at clarifying the relation of intake of sweet foods, sugar-sweetened beverages and spoonsful of sugar added to beverages and foods with MD among premenopausal and postmenopausal women.

\section{Methods}

\section{Study population and recruitment procedures}

While study population and recruitment procedures have been described elsewhere [36,37], here is a summary. Women of the study population have been recruited among those who received a screening mammogram between February 2001 and March 2002 in two private radiology clinics in Quebec City. Eligible women had to be classified as premenopausal or postmenopausal according to the Nurses' Health Study criteria [38], have no personal history of cancer or breast surgery, have no endocrine diseases, have never taken selective estrogen-receptor modulators, not be pregnant, and have not used exogenous hormones in the three months preceding the mammography. Of the 1574 women who have participated in the original study, we excluded 11 women who did not completed the food frequency questionnaire (FFQ), five women who followed a special diabetic diet and three women who reported extremely high $(>5000 \mathrm{kcal} /$ day $)$ or extremely low $(<600 \mathrm{kcal} /$ day $)$ caloric intake for the purpose of the present study. Thus the present analysis includes 1555 women (776 premenopausal and 779 postmenopausal). The study was approved by the Research Ethics Review Board-Hôpital Saint-Sacrement at the CHU de Québec. All study participants provided written informed consent.

\section{Data collection}

Height, weight, waist and hip circumferences were measured by a trained nurse at recruitment. Information on breast cancer risk factors and physical activity were collected during a phone interview performed by trained interviewers. Physical activity was assessed using the Nurses' Health Study II Activity and Inactivity Questionnaire [39] and then expressed as metabolic equivalent (MET) hours per week.

\section{Diet assessment}

Data on diet were collected with a 161-item, validated selfadministered semi-quantitative FFQ (97GP copyrighted at Harvard University, Boston, MA) [40,41]. A standard serving size was assigned for each item and its frequency of consumption over the previous year was selected between never, less than one serving per month, 1-3 servings per month, one serving per week, 2-4 servings per week, 5-6 servings per week, one serving per day, $2-3$ servings per day or more than three servings per day. From this FFQ, 14 items were classified as sweet foods (ice cream, chocolate, candy with chocolate, candy, homemade cookie, commercial cookie, brownie, donut, homemade cake, commercial cake, homemade pie, commercial pie, other homemade pastries and other commercial pastries), four items as sugar-sweetened beverages (cola with sugar, cola with sugar but caffeine free, other carbonated beverage with sugar and sweet fruit juice) and two items as spoonsful of sugar added to beverages and foods (tablespoon of jam, syrup or honey and teaspoon of sugar used).

\section{Digitization of mammograms and assessment of mammographic density}

Mammograms were digitized using a Kodak LS-85 laser film scanner. All mammograms were blindly evaluated by a trained reader within one month of each other. MD was assessed using interactive threshold Cumulus software, a computer assisted method [30]. A craniocaudal view of the right or left breast was randomly selected and MD was measured for each participant in batches of 100 images. Two measurements of MD were obtained: the proportion of the breast showing tissue density (percent density in \%) and the absolute amount of dense tissue (absolute density in $\mathrm{cm}^{2}$ ). Duplicates of images were introduced in each batch in order to evaluate reproducibility of measurement. The intra-class correlation coefficients were 0.98 and 0.98 and the inter-group coefficients of variation were $4 \%$ and $5 \%$ for percent and absolute density, respectively.

\section{Statistical analysis}

The frequency of consumption of each sweet item was transformed in number of servings per week, using the middle of each category when necessary. We created four groups of foods by adding the number of servings per week of 1- all 14 sweet foods, 2- all four sugar-sweetened beverages, 3- the two items related to spoonsful of sugar added and 4- all items aforementioned. Partial Spearman correlations between the number of servings per week and MD as continuous variables were estimated. As we found no specific categorization in the literature and that 
most of studies on sweet foods and breast cancer risk have used percentile categorization, the number of servings per week of each group was categorized in quartiles by using all women. Percent and absolute density were square roottransformed except for percent density among premenopausal women, in order to obtain a normal distribution of these variables. Then, multivariate-adjusted means of MD by quartile were estimated using generalized linear models, and the linear trend across quartiles was tested by using linear contrast with the median of servings per week within each of the quartiles as the value. Means of MD are presented as back-transformed values. For statistically significant results, additional multivariate-adjusted models were performed using categorizations of servings per week that are more useful for public health purposes. Potential confounders identified a priori and included in the adjusted models and correlations were age at mammography (year), body mass index $\left(\mathrm{BMI}, \mathrm{kg} / \mathrm{m}^{2}\right)$, age at menarche (years), age at first full-term pregnancy (years), number of full-term pregnancies, duration of breastfeeding (months), duration of use of oral contraceptive (years), duration of use of hormonal therapy (years), alcohol intake (servings/ week), family history of breast cancer (yes/no), number of biopsies, smoking status (nonsmoker, ex-smoker, current smoker), education (highest degree completed: primary or less, secondary, college, university), waist-to-hip ratio, physical activity (MET-h/week), calorie intake (kcal/day) and menopausal status (premenopausal, postmenopausal) when applicable. Further adjustment for intake of calcium (mg/day), intake of vitamin D (IU/day), season at time of mammography (winter, spring, summer, fall) and use of multivitamin-multimineral supplements (never, past, current user) had little or no influence on the estimates. Therefore, they were not added in the models.

Because the possible modifying effect of BMI and physical activity was reported in the literature, we also conducted exploratory analyses evaluating partial Spearman correlations of intake of sugar-sweetened beverages and sweet foods (the two groups that presented a statistically significant correlation with MD) with MD stratified by BMI $\left(\leq 25\right.$ and $>25 \mathrm{~kg} / \mathrm{m}^{2}$ ) and by physical activity ( $\leq$ median (21 MET-h/wk) and >median). All tests were 2-sided and a p-value $<0.05$ was considered statistically significant. All statistical analyses were carried out using the SAS (SAS Institute, Inc., Cary, NC) software system.

\section{Results}

\section{Study population}

Characteristics of the 1555 women included in the analyses are described in Table 1 . In summary, the mean age of the women was 54.1 years, with a mean of 46.7 years for premenopausal women and 61.4 years for postmenopausal women. As expected, postmenopausal women had lower percent and absolute densities compared with premenopausal women (18.5 versus $42.0 \%$ and 23.3 versus $46.5 \mathrm{~cm}^{2}$ respectively). On average, postmenopausal women consumed more sweet foods (11.8 versus 7.7 servings per week), spoonsful of sugar added (8.2 versus 6.9 servings per week) and all sweet items grouped (21.9 versus 16.8 servings per week) than premenopausal women, with a higher total caloric intake per day. The frequency of sugar-sweetened beverages intake was similar in both groups (1.9 versus 2.1 servings per week for postmenopausal and premenopausal women respectively).

\section{Consumption of sugar-sweetened beverages}

The associations between consumption of sugar-sweetened beverages and MD are shown in Table 2. Among all women, ascending quartiles of sugar-sweetened beverages intake was positively associated with percent density $\left(P_{\text {trend }}=0.17, r=0.054(P=0.038)\right)$ and absolute density $\left(P_{\text {trend }}=0.040, r=0.051(P=0.049)\right)$. For increasing weekly servings of sugar-sweetened beverages (none, $<1$, $1-3$ and $>3$ ), MD was respectively 26.2, 27.5, 27.7, 29.2\% $\left(P_{\text {trend }}=0.046\right.$, Figure $\left.1 \mathrm{~A}\right)$ and $31.6,32.7,32.9,36.4 \mathrm{~cm}^{2}$ $\left(P_{\text {trend }}=0.016\right.$, Figure $\left.1 \mathrm{~B}\right)$. When stratified by menopausal status, the positive association between sugar-sweetened beverages intake and absolute density remained significant among premenopausal $\left(P_{\text {trend }}=0.007, r=0.088\right.$ $(P=0.016))$ but not among postmenopausal women $\left(P_{\text {trend }}=0.96, r=0.013(P=0.74)\right)$. For increasing weekly servings of sugar-sweetened beverages (none, $<1,1-3$ and $>3$ ), absolute density was respectively 42.8, 43.9, 48.3 and $50.8 \mathrm{~cm}^{2}$ among premenopausal women $\left(P_{\text {trend }}=\right.$ 0.007, Figure 1C).

\section{Consumption of sweet foods}

The associations between consumption of sweet foods and MD are also shown in Table 2. Among postmenopausal women, ascending quartiles of sweet foods intake was positively associated with percent density $\left(P_{\text {trend }}=0.036\right.$, $r=0.073(P=0.048))$. For increasing weekly servings of sweet foods $(<3,3-6,7-14$ and $\geq 15)$, percent density was respectively $16.2,16.3,17.4$ and $19.1 \%$ ( $P_{\text {trend }}=0.049$, Figure 1D). However, we observed no association between sweet foods consumption and absolute density among postmenopausal women $\left(P_{\text {trend }}=0.27, r=0.043(P=0.24)\right)$. Furthermore, the consumption of this group of foods was not associated with any measure of MD among all or premenopausal women.

\section{Consumption of spoonsful of sugar added and total of all sweet items}

The consumption of spoonsful of sugar added and the total of all sweet items were not associated with MD among all women or within strata of menopausal status (Table 2). 
Table 1 Characteristics of the study population

\begin{tabular}{|c|c|c|c|}
\hline & Total $n=1555$ & Premenopausal $\mathrm{n}=776^{*}$ & Postmenopausal $n=779 * *$ \\
\hline Age (years), mean (SD) & $54.1(9.4)$ & $46.7(4.6)$ & $61.4(6.8)$ \\
\hline Age at $1^{\text {st }}$ full-term pregnancy (years), mean (SD) ${ }^{a}$ & $25.7(4.2)$ & $26.3(4.2)$ & $25.2(4.1)$ \\
\hline Body mass index $\left(\mathrm{kg} / \mathrm{m}^{2}\right)$, mean (SD) & $26.1(4.7)$ & $25.2(4.5)$ & $27.1(4.7)$ \\
\hline Waist-to-hip ratio, mean (SD) & $0.8(0.1)$ & $0.8(0.1)$ & $0.8(0.1)$ \\
\hline Age at menarche (years), mean (SD) & $12.7(1.6)$ & $12.8(1.6)$ & $12.7(1.6)$ \\
\hline Alcohol intake (drinks/week), mean (SD) & $3.0(4.1)$ & $3.4(3.8)$ & $2.5(4.4)$ \\
\hline Physical activity (MET-h/week), mean (SD) & $26.3(22.8)$ & $27.0(22.3)$ & $25.7(23.4)$ \\
\hline Caloric intake (kcal/day), mean (SD) & $1941.1(585.8)$ & $1911.5(521.4)$ & $1970.6(642.5)$ \\
\hline Percent density (\%), mean (SD) & $30.2(24.0)$ & $42.0(24.4)$ & $18.5(16.8)$ \\
\hline Absolute density $\left(\mathrm{cm}^{2}\right)$, mean (SD) & $34.9(27.7)$ & $46.5(28.7)$ & $23.3(21.0)$ \\
\hline Sugar-sweetened beverages ${ }^{\mathrm{b}}$ (servings/week), mean (SD) & $2.0(4.0)$ & $2.1(4.4)$ & $1.9(3.5)$ \\
\hline Sweet foods ${ }^{c}$ (servings/week), mean (SD) & $9.8(9.7)$ & $7.7(7.6)$ & $11.8(11.0)$ \\
\hline Spoonsful of sugar added (servings/week), mean (SD) & $7.6(11.0)$ & $6.9(11.0)$ & $8.2(10.9)$ \\
\hline Total of all sweet items (servings/week), mean (SD) & $19.3(17.4)$ & $16.8(15.3)$ & $21.9(18.8)$ \\
\hline Parity (yes), n (\%) & $1167(75.1)$ & $584(75.3)$ & $583(74.8)$ \\
\hline Breastfeeding (yes), n (\%) ${ }^{\mathrm{a}}$ & $532(45.6)$ & $363(62.2)$ & $169(29.0)$ \\
\hline Use of hormonal therapy (yes), n (\%) & $347(22.4)$ & $45(5.8)$ & $302(39.1)$ \\
\hline Use of oral contraceptive (yes), n (\%) & $1128(72.7)$ & $712(91.9)$ & $416(53.5)$ \\
\hline Family history of breast cancer (yes), n (\%) & $521(33.5)$ & $284(36.6)$ & $237(30.4)$ \\
\hline Breast biopsy (yes), n (\%) & $238(15.3)$ & $112(14.4)$ & $126(16.2)$ \\
\hline \multicolumn{4}{|l|}{ Education (highest degree completed), n (\%) } \\
\hline Primary or less & $255(16.4)$ & $51(6.6)$ & $204(26.2)$ \\
\hline Secondary & $510(32.8)$ & $242(31.2)$ & $268(34.4)$ \\
\hline College & $304(19.6)$ & $206(26.6)$ & $98(12.6)$ \\
\hline University & $486(31.3)$ & $277(35.7)$ & $209(26.8)$ \\
\hline \multicolumn{4}{|l|}{ Smoking status, n (\%) } \\
\hline Nonsmoker & $811(52.2)$ & $354(45.6)$ & $457(58.7)$ \\
\hline Ex-smoker & $524(33.7)$ & $306(39.4)$ & $218(28.0)$ \\
\hline Current smoker & $220(14.1)$ & $116(15.0)$ & $104(13.4)$ \\
\hline
\end{tabular}

*Missing values for sweet foods $(n=2)$, sugar-sweetened beverages $(n=5)$ and total of all sweets $(n=7)$.

**Missing values for sweet foods $(n=11)$, sugar-sweetened beverages $(n=2)$, spoonsful of sugar added $(n=1)$ and total of all sweets $(n=14)$.

${ }^{a}$ Among parous women.

${ }^{\mathrm{b}}$ Including cola with sugar, cola with sugar but caffeine free, other carbonated beverage with sugar and sweet fruits juice.

Including ice cream, chocolate, candy with chocolate, candy, homemade cookie, commercial cookie, brownie, donut, homemade cake, commercial cake,

homemade pie, commercial pie, other homemade pastries and other commercial pastries.

${ }^{d}$ Including teaspoons of sugar added to beverages and foods and tablespoons of jam, honey and syrup.

Abbreviations: SD standard deviation, MET-h/wk Metabolic equivalent hours per week.

\section{Stratified analysis by BMI and physical activity}

Partial Spearman correlations of intake of sweet foods or sugar-sweetened beverages with percent or absolute density stratified by BMI or physical activity are detailed in Additional file 1. Regarding the positive correlation observed between the intake of sugar-sweetened beverages and $\mathrm{MD}$ among all women, this correlation remained significant only among the stratum of less active women for percent density $(r=0.080, P=0.030)$ but not for absolute density $(r=0.060, P=0.103)$. As to the correlation observed between sweet foods intake and percent density among postmenopausal women, this positive correlation remained significant only for those who are less active $(r=0.145, P=0.005)$. No other significant correlation was observed within strata of BMI or physical activity.

\section{Discussion}

In this study, we found that sugar-sweetened beverage intake was positively associated with MD among all women or limited to premenopausal women. We also found that the intake of sweet foods including mostly desserts was positively associated with MD in postmenopausal women. 
Table 2 Associations ${ }^{a}$ of consumption of sweets with mammographic density among all women and by menopausal status

\begin{tabular}{|c|c|c|c|c|c|c|c|c|c|}
\hline \multirow{3}{*}{$\begin{array}{l}\text { Quartiles* of } \\
\text { servings per } \\
\text { week }\end{array}$} & \multicolumn{3}{|c|}{ All women } & \multicolumn{3}{|c|}{ Premenopausal women } & \multicolumn{3}{|c|}{ Postmenopausal women } \\
\hline & & Percent density & Absolute density & & Percent density & Absolute density & & Percent density & Absolute density \\
\hline & $\mathrm{n}^{* *}$ & $\%[95 \% \mathrm{Cl}]^{\mathrm{a}}$ & $\mathrm{cm}^{2}[95 \% \mathrm{Cl}]^{\mathrm{a}}$ & $\mathrm{n}^{* *}$ & $\%[95 \% \mathrm{Cl}]^{\mathrm{a}}$ & $\mathrm{cm}^{2}\left[95 \% \mathrm{Cl}^{\mathrm{a}}\right.$ & $\mathrm{n}^{* *}$ & $\%[95 \% \mathrm{Cl}]^{\mathrm{a}}$ & $\mathrm{cm}^{2}\left[95 \% \mathrm{Cl}^{\mathrm{a}}\right.$ \\
\hline \multicolumn{10}{|c|}{ Sugar-sweetened beverages ${ }^{b}$} \\
\hline 0 & 334 & $26.3[24.4-28.1]$ & 31.6 [29.3-34.0] & 140 & $41.8[38.4-45.1]$ & 42.8 [38.6-47.3] & 194 & 16.6 [14.8-18.5] & $22.7[20.2-25.4]$ \\
\hline $0.01-0.43$ & 391 & 28.5 [26.8-30.2] & 34.1 [31.9-36.4] & 210 & $42.5[39.7-45.2]$ & 45.5 [41.9-49.4] & 181 & 18.8 [16.9-20.9] & $24.2[21.6-27.0]$ \\
\hline $0.44-1.69$ & 433 & $26.8[25.2-28.4]$ & 31.5 [29.5-33.5] & 220 & $40.4[37.8-43.1]$ & $43.9[40.4-47.4]$ & 213 & 17.0 [15.3-18.8] & 21.1 [18.9-23.4] \\
\hline$>1.69$ & 390 & $28.8[27.0-30.7]$ & $35.6[33.3-38.1]$ & 201 & $44.0[41.2-47.0]$ & $51.1[47.0-55.4]$ & 189 & $17.1[15.2-19.1]$ & 22.9 [20.3-25.6] \\
\hline$P_{\text {trend }}$ & & 0.172 & 0.040 & & 0.240 & 0.007 & & 0.731 & 0.958 \\
\hline Spearman $r(P)$ & & $0.054(0.038)$ & $0.051(0.049)$ & & $0.049(0.185)$ & $0.088(0.016)$ & & $0.026(0.492)$ & $0.013(0.735)$ \\
\hline \multicolumn{10}{|l|}{ Sweet foods ${ }^{c}$} \\
\hline $0-2.95$ & 380 & $27.9[26.1-29.8]$ & $33.9[31.6-36.4]$ & 219 & $43.5[40.7-46.4]$ & $47.4[43.6-51.4]$ & 161 & 16.2 [14.2-18.3] & $22.2[19.5-25.1]$ \\
\hline $2.96-6.79$ & 390 & 26.7 [25.1-28.5] & 32.1 [29.9-34.3] & 231 & $42.2[39.6-44.7]$ & $45.2[41.7-48.7]$ & 159 & 15.9 [14.0-17.9] & 21.0 [18.4-23.8] \\
\hline $6.80-11.90$ & 383 & 28.1 [26.4-29.9] & $34.4[32.2-36.7]$ & 195 & $43.0[40.2-45.9]$ & 48.9 [44.9-53.0] & 188 & 17.4 [15.6-19.3] & $22.7[20.3-25.3]$ \\
\hline$>11.90$ & 389 & 27.9 [26.1-29.9] & 32.7 [30.3-35.2] & 129 & 38.8 [35.1-42.5] & $41.2[36.6-46.1]$ & 260 & 18.8 [17.0-20.7] & 23.7 [21.3-26.1] \\
\hline$P_{\text {trend }}$ & & 0.717 & 0.748 & & 0.065 & 0.077 & & 0.036 & 0.266 \\
\hline Spearman $r(P)$ & & $0.008(0.772)$ & $-0.006(0.829)$ & & $-0.052(0.161)$ & $-0.044(0.233)$ & & $0.073(0.048)$ & $0.043(0.242)$ \\
\hline \multicolumn{10}{|c|}{ Spoonsful of sugar added ${ }^{d}$} \\
\hline $0-0.56$ & 428 & 27.0 [25.4-28.7] & 32.5 [30.4-34.6] & 234 & 42.1 [39.4-44.7] & 44.2 [40.7-47.8] & 194 & 17.2 [15.3-19.1] & 23.0 [20.5-25.7] \\
\hline $0.57-3.01$ & 392 & 26.7 [25.0-28.4] & $32.3[30.2-34.6]$ & 211 & 41.5 [38.8-44.2] & $46.2[42.6-50.0]$ & 181 & 16.4 [14.6-18.4] & 21.3 [18.9-23.9] \\
\hline $3.02-9.31$ & 327 & $28.6[26.7-30.5]$ & $34.2[31.8-36.7]$ & 148 & $41.8[38.6-45.0]$ & 46.3 [41.9-50.8] & 179 & $18.2[16.2-20.2]$ & 23.3 [20.8-26.1] \\
\hline$>9.31$ & 407 & 28.4 [26.7-30.2] & $34.2[32.0-36.5]$ & 183 & $43.4[40.4-46.3]$ & $48.1[44.1-52.3]$ & 224 & 17.5 [15.8-19.4] & 22.8 [20.5-25.3] \\
\hline$P_{\text {trend }}$ & & 0.164 & 0.211 & & 0.415 & 0.208 & & 0.594 & 0.807 \\
\hline Spearman $r(P)$ & & $0.030(0.241)$ & $0.026(0.311)$ & & $0.034(0.362)$ & $0.055(0.138)$ & & $0.016(0.661)$ & $0.003(0.929)$ \\
\hline \multicolumn{10}{|c|}{ Total of all sweet items } \\
\hline $0-7.14$ & 380 & $26.2[24.5-28.1]$ & $31.7[29.4-34.1]$ & 219 & $41.3[38.5-44.0]$ & $43.5[39.9-47.3]$ & 161 & 16.0 [14.0-18.2] & $21.8[19.0-24.8]$ \\
\hline $7.15-14.0$ & 383 & $29.1[27.4-31.0]$ & 34.9 [32.7-37.3] & 213 & $45.5[42.8-48.2]$ & $49.3[45.6-53.2]$ & 170 & 17.9 [15.9-20.0] & $23.1[20.5-25.9]$ \\
\hline
\end{tabular}


Table 2 Associations ${ }^{a}$ of consumption of sweets with mammographic density among all women and by menopausal status (Continued)

\begin{tabular}{|c|c|c|c|c|c|c|c|c|c|}
\hline $14.01-26.25$ & 384 & 27.7 [25.9-29.4] & $33.4[31.2-35.7]$ & 188 & $40.2[37.3-43.1]$ & $46.1[42.2-50.2]$ & 196 & 17.8 [16.0-19.8] & 22.8 [20.4-25.4] \\
\hline$>26.25$ & 387 & 27.6 [25.8-29.5] & $32.9[30.6-35.4]$ & 149 & $41.5[38.0-45.0]$ & $44.7[40.2-49.6]$ & 238 & 17.4 [15.6-19.3] & $22.7[20.3-25.2]$ \\
\hline$P_{\text {trend }}$ & & 0.740 & 0.909 & & 0.503 & 0.830 & & 0.536 & 0.794 \\
\hline Spearman $r(P)$ & & $0.026(0.311)$ & $0.017(0.513)$ & & $0.001(0.984)$ & $0.019(0.609)$ & & $0.044(0.238)$ & $0.019(0.604)$ \\
\hline
\end{tabular}

${ }^{a}$ All analyses (linear models and Spearman correlations) were adjusted for: Total caloric intake per day, age at mammography, body mass index, waist-to-hip ratio, menopausal status (for total women only), age at menarche, parity, number of full-term pregnancies, age at first full-term pregnancy, duration of use of hormonal contraceptive, duration of use of hormonal therapy, alcohol intake, physical activity, family history of breast cancer, number of breast biopsies, smoking status, education and breastfeeding. Percent and absolute density were square root-transformed for all analyses, except for percent density among premenopausal, to obtain an approximate normal distribution. Means are presented as back-transformed values for these analyses.

bIncluding cola with sugar, cola with sugar but caffeine free, other carbonated beverage with sugar and sweet fruits juice.

Including ice cream, chocolate, candy with chocolate, candy, homemade cookie, commercial cookie, brownie, donut, homemade cake, commercial cake, homemade pie, commercial pie, other homemade pastries and other commercial pastries.

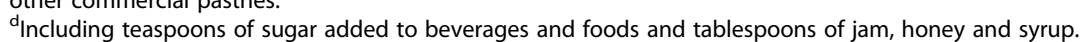

*Quartiles are made using all women.

**Number do not add up because of missing data.

The statistically significant results are in bold.

Abbreviations: $\mathrm{Cl}$ confidence interval, $r$ correlation, $P_{\text {trend }} \mathrm{p}$-value for linear contrast test. 

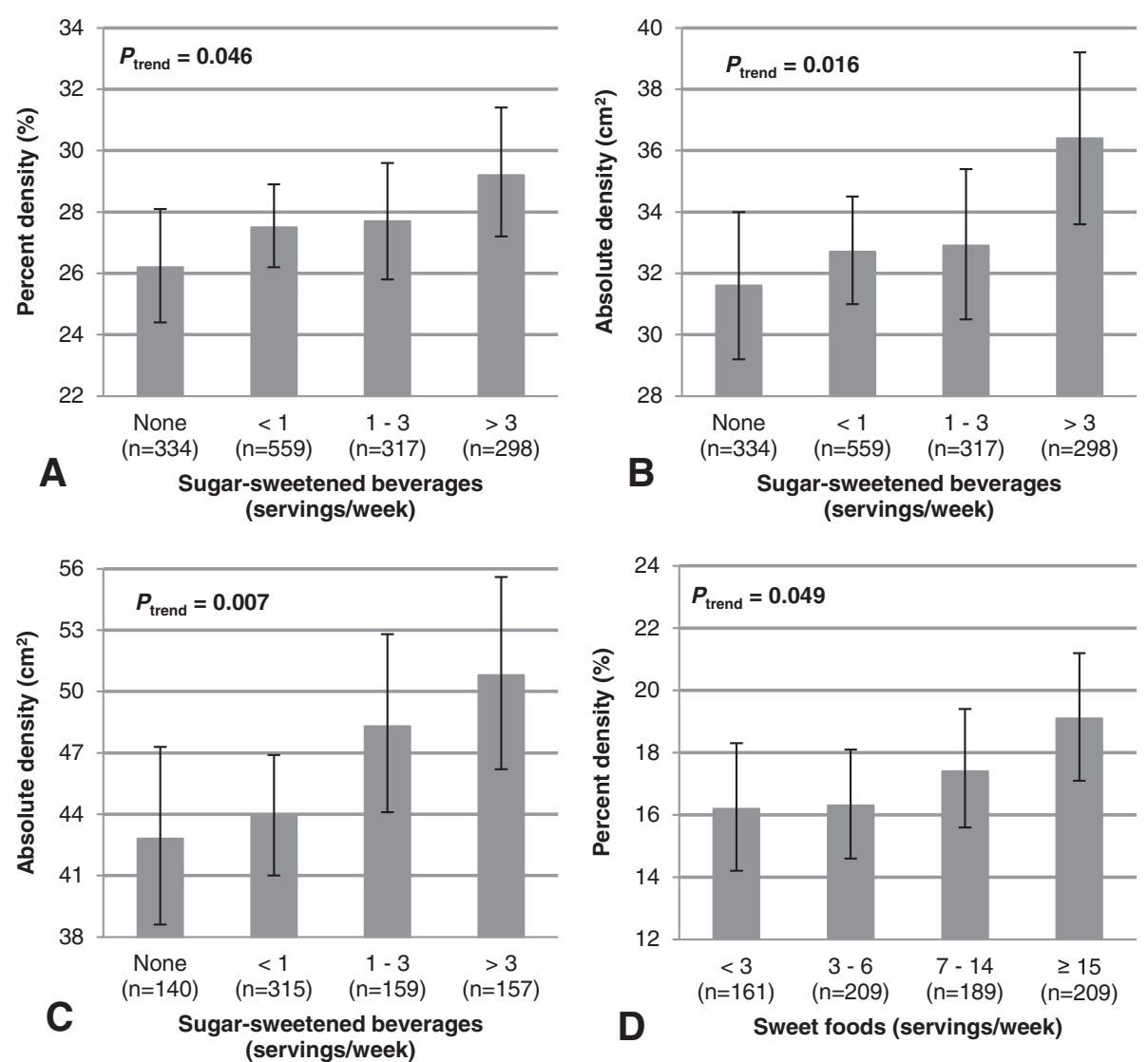

Figure 1 Mammographic density according to number of servings per week of beverages or sweet foods. Percent (A) and absolute (B) density according to weekly servings of sugar-sweetened beverages among all women. Absolute density according to weekly servings of sugar-sweetened beverages among premenopausal women (C). Percent density according to weekly servings of sweet foods among postmenopausal women (D). Percent and absolute density were square root-transformed for all analyses, except for percent density among premenopausal, to obtain an approximate normal distribution. Means are presented as back-transformed values for these analyses. Error lines represent the $95 \%$ confidence intervals. All analyses were adjusted for total caloric intake, age at mammography, BMI, waist-to-hip ratio, age at menarche, number of full-term pregnancies, age at first full-term pregnancy, duration of use of hormonal contraceptive, duration of use of hormonal therapy, alcohol intake, physical activity, family history of breast cancer, number of biopsies, smoking status, education, breastfeeding and menopausal status when applicable. $P_{\text {trend }}=p$-value for linear contrast test.

Among all women, those who had a sugar-sweetened beverages intake of more than three servings per week presented a 3\% difference in percent density compared with those who did not drink this type of beverages (29.2\% versus $26.2 \%)$. By comparison, it has been shown that healthy women at high risk of developing breast cancer who received tamoxifen for 54 months had a reduction of $6.4 \%$ in MD [42], and since tamoxifen can reduce the risk of breast cancer by $30-50 \%$ in high-risk women [43,44], an increase of about $3 \%$ in MD is not negligible in terms of breast cancer risk. In our population the consumption of sugar-sweetened beverages is not very high, but in the United States, a citizen consumes on average 12 servings of soda per week ( 1 serving $=1$ bottle of $355 \mathrm{ml}$ ) of which $58 \%$ contain sugar [1].

To our knowledge, the association between consumption of sweet foods and MD has been assessed by one group other than ours [34]. In this cross-sectional study of 64 Malaysian women aged between 35 and 75 years, Voon and Chelliah analyzed the association between consumption of sweet foods summed in one group and MD divided in two groups (low: group I and II and high: group III and IV of the BI-RADS classification) and found a significant positive association [Odds ratio $(\mathrm{OR})=3.6,95 \% \mathrm{CI}(1.2-10.8)$ ]. Unfortunately, there is no mention of which sweet foods were included in their group. Moreover, no stratified analysis by menopausal status was performed due to their small sample size. Several studies have examined the link between the consumption of desserts and breast cancer risk $[4,9-13,19,20,22,25,26,45]$ and found a positive association $[4,9-13,19,20]$. Among them, only one had stratified their analyses by menopausal status [20] and one had stratified by age [4] which can serve as a proxy for menopausal status. Tavani et al. [4] found a positive association 
between dessert intake and breast cancer risk for all women and, when stratified by age, this association was significant only among women aged 60 years or more. In contrast, Bradshaw et al. [20] found a positive association between dessert intake and breast cancer risk among premenopausal and postmenopausal women with a slightly higher effect among premenopausal women. In our study, the positive association between sweet foods intake and MD is shown for postmenopausal only. Thus, our results suggested that a higher consumption of sweet foods may lead to higher MD and eventually higher breast cancer risk, at least for postmenopausal women. Since we observed no association between sweet foods intake and MD among premenopausal women, MD may not be the only pathway that could link sweet foods intake to breast cancer risk. The group of sweet foods is composed in majority of items that have a lot of sugar but also a lot of fat, and the consumption of fat has been positively associated with breast cancer risk and MD among postmenopausal in some studies [46-49]. However, the role of fat consumption in breast cancer risk or on MD is still controversial [49-52].

In a longitudinal study, Masala et al. [35] assessed the relation between consumption at baseline of a group of foods named sugar (that included jam, honey and sugar added to coffee, tea and yogurt) derived from a FFQ of 160 items and MD evaluated 5 years after enrollment according to Wolf's classification (dichotomized in high $(\mathrm{P} 2+\mathrm{DY})$ and low $(\mathrm{N} 1+\mathrm{P} 1))$. Their study population was composed of 1668 women aged 53 years on average and $62.4 \%$ were postmenopausal at baseline [35]. They found that women among the highest tertile of sugar consumption had higher MD, but the association was not statistically significant $[\mathrm{OR}=1.22$; $95 \% \mathrm{CI}(0.92-1.61), P=0.17]$. In our population, we observed a similar tendency with the consumption of spoonsful of sugar added, which is comparable to their sugar group, which was not statistically significant, agreeing with their results. Unfortunately, among studies on breast cancer risk, none of them made an analysis with consumption of spoonsful of sugar added similar to ours. Nonetheless, a possible explanation for the lack of association between the consumption of spoonsful of sugar added and MD may be related to the composition of table sugar. Contrary to commercial desserts and sweet drinks which contain more grams of fructose than glucose, table sugar contains equal amounts of fructose and glucose [53]. Fructose and glucose are both simple sugars but they are absorbed and metabolized by different pathways in the organism and some authors have suggested that fructose could be more harmful than glucose to human health due to this difference [53,54]. It has been recently suggested that excessive consumption of fructose may increase breast cancer risk [7].

In the present study, we observed a positive association between sugar-sweetened beverages intake and MD among all women and particularly among premenopausal women. To our knowledge, this relationship was not assessed in another study. Nonetheless, our results are consistent with those from Witte and colleagues [14] who found a positive association between sweetened beverages intake and breast cancer risk among premenopausal women. Similarly, Potischman et al. [18] found a positive association with consumption of sweet items that included beverages, foods and spoonsful of sugar added among their study population composed of premenopausal women only. They evaluated the contribution of each component of that food group and found that the major contributor in percentage was regular cola soft drinks. However, the creation of a new group of full-sugar drinks (including all soft drinks caffeinated or not, and other fruit drinks with sugar) did not reveal any association. In contrast to the sweet foods group, the sugar-sweetened beverages group is composed of drinks mostly made of sugar (made of high-fructose corn syrup) and water suggesting that the positive association shown with the consumption of those drinks and MD or breast cancer risk among premenopausal women would be more related to the consumption of sugar, particularly fructose.

Stratified analyses by BMI and physical activity reveal that our association of sugar-sweetened beverages or sweet foods intake with MD is stronger among all less active women or among postmenopausal less active women respectively. Two breast cancer risk studies stratified their analyses by BMI and physical activity. One found that the association between intake of desserts or spoonsful of sugar and breast cancer risk did not differ within strata of BMI [4] and the other one found a nearly doubling risk with increased intake of desserts among more active (>7.54 MET-h/wk) compared with inactive women (0 MET-h/wk) and a stronger association among women with a lower BMI $\left(<25 \mathrm{~kg} / \mathrm{m}^{2}\right)$ [20]. However, these analyses relied on different thresholds for stratification and did not assess associations by menopausal status, making comparison difficult.

Several biological mechanisms may explain the higher MD observed in this study with higher sweet items intake. Intake of sugar seems to have an effect on cellular proliferation in general [7] and also on breast tumor cells in vitro [8], and increases incidence of tumors in animal models [55,56]. Moreover, an in vitro study on breast tumor cells has shown that while fructose appears to increase cell invasion and migration, glucose seems to increase cell proliferation [8]. These observations suggest that intake of sweet items could enhance cellular proliferation in breast tissues and could increase MD. In humans, excessive sugar consumption is also associated with an increase in production of insulin $[7,57]$ that, in turn, can increase insulin-like growth factor-I (IGF-I) $[58,59]$, a growth factor that has mitogenic and anti- 
apoptotic effects on cells. These effects were seen in both normal and abnormal breast cells [60-62]. Wang et al. found that feeding mice with a high sucrose diet could promote the proliferation and tumorigenesis of intestinal epithelial cells by increasing insulin and IGF-I levels [63]. In fact, IGF-I levels have been positively associated with breast cancer risk [64-66] and MD [36,67,68], particularly among premenopausal women. Regarding insulin, a positive association with breast cancer risk has been shown for postmenopausal women [69]. However, the possible effect of insulin levels on MD has not yet been shown [70,71]. Another possible mechanism of action of sugar consumption is through its effect on circulating levels of 25-hydroxyvitamin D $(25(\mathrm{OH}) \mathrm{D})$, the principal circulating vitamin D metabolite. This mediated action is likely because sugar-sweetened beverages, particularly colas, have been shown to decrease levels of serum 25(OH)D in an animal model [72] and in a study involving children [73]. At a cellular level, vitamin D (revealed by the levels of $25(\mathrm{OH}) \mathrm{D}$ as its biomarker) has been found to have anti-proliferative and pro-apoptotic effects [74]. Furthermore, low levels of $25(\mathrm{OH}) \mathrm{D}$ were found to be associated with an increase in breast cancer risk and MD among premenopausal women [75-77]. All of these hypotheses need to be confirmed with additional studies.

\section{Strengths and limitations}

This study has several strengths. Firstly, the size of the study sample is relatively large and the equal number of premenopausal and postmenopausal women allows stratified analyses with enough power. Secondly, the breast mammographic images are of great quality. Almost all mammograms were done with equipment (LORAD M4) accredited by the Canadian Association of Radiology in order to satisfy the high quality standards of the Quebec breast cancer screening program. Thirdly, all measures of $\mathrm{MD}$ were done using a computer-assisted method with a trained reader without any information on women in a short period of time. Furthermore, the reader's reliability of readings was high. Thus, misclassification of MD is unlikely and, if present, it should not have biased our results. Fourthly, the FFQ used in this study was validated in several studies for its accuracy $[40,41]$. Finally, adjustment was made for factors known or suspected to be related to $\mathrm{MD}$ and for total caloric intake to control for most of the potential confounding biases. Since all of the women in this study were Caucasian, analyses were not adjusted for ethnicity.

This study has also some limitations. We aimed at clarifying the effect of consumption of sweet foods on MD because they contain a lot of sugar, but some of these foods also contain other nutrients, like fat, that may cause residual confounding. Thus, the association observed between sweet foods intake and MD among postmenopausal women could be due to nutrients other than sugar. However, the sugar-sweetened beverages group is mostly composed of sugar. Therefore, the association found with sugar-sweetened beverage intake and MD among premenopausal women supports our hypothesis that higher consumption of sugar can lead to higher MD. Misclassification in the frequency of consumption of food items is possible with the use of the FFQ. Participants have to give an estimation of the frequency of consumption of an item over the previous year. However, differential bias is unlikely because answers inaccuracies can hardly be related to $\mathrm{MD}$ and the misclassification can only lead to an underestimation of the effect. Furthermore, the crosssectional design of this study does not allow causal interpretation and prospective studies are necessary to establish causality. We also cannot exclude that our findings may be due to chance because we evaluated several associations. Type I errors or false-positive results are therefore possible. Finally, it is $\mathrm{p}$ that power was insufficient for stratified analyses by BMI and physical activity in each menopausal group and therefore these results should be interpreted with caution.

\section{Conclusions}

This study found that higher consumption of sweet foods among postmenopausal women and higher consumption of sugar-sweetened beverages among premenopausal women are associated with MD. Given the small number of studies that examined the relationship between intake of sweet items and MD, these associations need to be confirmed by other studies. The difference in MD found in our study might not be very high, but it may not be neglected in a global strategic plan to prevent breast cancer by reducing MD. Considering the worldwide increase in sugar consumption and all the health problems it is related to, it is important to continue research on this subject and begin to inform the public about the adverse effects of sugar consumption.

\section{Additional file}

Additional file 1: Partial Spearman correlations of sugar-sweetened beverages and sweet foods intake with MD stratified by BMI and physical activity among all, premenopausal and postmenopausal women.

\section{Abbreviations}

MD: Mammographic density; WHO: World health organization; FAO: Food and agriculture organization of the United Nations; FFQ: Food frequency questionnaire; BMl: Body mass index; MET-h/wk: Metabolic equivalent hours per week; OR: Odds ratio; IGF-I: Insulin-like growth factor; 25(OH)D: 25-hydroxyvitamin D.

\section{Competing interest}

The authors declare that they have no competing interest. 


\section{Authors' contributions}

CSD performed statistical analysis with input from CD, and wrote the first draft of the manuscript. ID assisted in the interpretation of findings and was involved in the critical revising of the manuscript. CD conceived the study, participated in statistical analysis, in the interpretation of findings, in the drafting and revision of the manuscript. All authors read and approved the final manuscript.

\section{Acknowledgments}

This study was supported by grants from the Canadian Breast Cancer Research Alliance. CD is a Junior Investigator of the Canadian Cancer Society (2011-700657). We thank Jacques Brisson and Sylvie Bérubé for their valuable contributions to the initial study, and Caty Blanchette for her valuable help in data analysis. We are grateful to the Clinique radiologique Audet and the Clinique de radiologie Saint-Pascal for their excellent collaboration.

\section{Author details}

'Département de médecine sociale et préventive, Centre de recherche sur le cancer, Université Laval, 2325, rue de I'Université, G1V 0A6 Quebec City, QC, Canada. ${ }^{2}$ Axe Oncologie, Centre de recherche du CHU de Québec, Hôpital du Saint-Sacrement, 1050, chemin Ste-Foy, G1S 4L8 Quebec City, QC, Canada. ${ }^{3}$ Centre des maladies du sein Deschênes-Fabia, Hôpital St-Sacrement du CHU de Québec, 1050, chemin Ste-Foy, G1S 4L8 Quebec, QC, Canada.

Received: 17 December 2013 Accepted: 27 May 2014

Published: 26 June 2014

\section{References}

1. Lustig RH, Schmidt LA, Brindis CD: Public health: the toxic truth about sugar. Nature 2012, 482(7383):27-29.

2. Diet, Nutrition and the Prevention of Chronic Diseases. Report of a Joint WHO/ FAO Expert Consultation. WHO Technical Report Series No. 916. Geneva: World Health Organization; 2003.

3. Alemany M: Utilization of dietary glucose in the metabolic syndrome. Nutr Metab (Lond) 2011, 8(1):74.

4. Tavani A, Giordano L, Gallus S, Talamini R, Franceschi S, Giacosa A, Montella $\mathrm{M}$, La Vecchia C: Consumption of sweet foods and breast cancer risk in Italy. Ann Oncol 2006, 17(2):341-345.

5. Michaud DS, Fuchs CS, Liu S, Willett WC, Colditz GA, Giovannucci E: Dietary glycemic load, carbohydrate, sugar, and colorectal cancer risk in men and women. Cancer Epidemiol Biomarkers Prev 2005, 14(1):138-147.

6. Friberg E, Wallin A, Wolk A: Sucrose, high-sugar foods, and risk of endometrial cancer-a population-based cohort study. Cancer Epidemiol Biomarkers Prev 2011, 20(9):1831-1837.

7. Liu H, Heaney AP: Refined fructose and cancer. Expert Opin Ther Targets 2011, 15(9):1049-1059.

8. Monzavi-Karbassi B, Hine RJ, Stanley JS, Ramani VP, Carcel-Trullols J, Whitehead TL, Kelly T, Siegel ER, Artaud C, Shaaf S, Saha R, Jousheghany F, Henry-Tillman R, Kieber-Emmons T: Fructose as a carbon source induces an aggressive phenotype in MDA-MB-468 breast tumor cells. Int J Oncol 2010, 37(3):615-622.

9. Lubin JH, Burns PE, Blot WJ, Ziegler RG, Lees AW, Fraumeni JF Jr: Dietary factors and breast cancer risk. Int J Cancer 1981, 28(6):685-689.

10. Iscovich JM, Iscovich RB, Howe G, Shiboski S, Kaldor JM: A case-control study of diet and breast cancer in Argentina. Int J Cancer 1989, 44(5):770-776

11. Richardson S, Gerber M, Cenee S: The role of fat, animal protein and some vitamin consumption in breast cancer: a case control study in southern France. Int J Cancer 1991, 48(1):1-9.

12. Landa MC, Frago N, Tres A: Diet and the risk of breast cancer in Spain. Eur J Cancer Prev 1994, 3(4):313-320.

13. Franceschi S, Favero A, La Vecchia C, Negri E, Dal Maso L, Salvini S, Decarli A, Giacosa A: Influence of food groups and food diversity on breast cancer risk in Italy. Int J Cancer 1995, 63(6):785-789.

14. Witte JS, Ursin G, Siemiatycki J, Thompson WD, Paganini-Hill A, Haile RW: Diet and premenopausal bilateral breast cancer: a case-control study. Breast Cancer Res Treat 1997, 42(3):243-251.

15. Favero A, Parpinel M, Franceschi S: Diet and risk of breast cancer: major findings from an Italian case-control study. Biomed Pharmacother 1998, 52(3):109-115.
16. Augustin LS, Dal Maso L, La Vecchia C, Parpinel M, Negri E, Vaccarella S, Kendall CW, Jenkins DJ, Francesch S: Dietary glycemic index and glycemic load, and breast cancer risk: a case-control study. Ann Oncol 2001, 12(11):1533-1538.

17. Bala DV, Patel DD, Duffy SW, Cherman S, Patel PS, Trivedi J, Pinaki P, Pandey $P$, Patel R: Role of dietary intake and biomarkers in risk of breast cancer: a case control study. Asian Pac J Cancer Prev 2001, 2(2):123-130.

18. Potischman N, Coates RJ, Swanson CA, Carroll RJ, Daling JR, Brogan DR, Gammon MD, Midthune D, Curtin J, Brinton LA: Increased risk of earlystage breast cancer related to consumption of sweet foods among women less than age 45 in the United States. Cancer Causes Control 2002, 13(10):937-946.

19. Saleh F, Reno W, Ibrahim G, Behbehani A, Dashti H, Asfar S: The first pilot study on characteristics and practice patterns of Kuwaiti breast cancer patients. J Environ Pathol Toxicol Oncol 2008, 27(1):61-75.

20. Bradshaw PT, Sagiv SK, Kabat GC, Satia JA, Britton JA, Teitelbaum SL, Neugut $\mathrm{Al}$, Gammon MD: Consumption of sweet foods and breast cancer risk: a case-control study of women on Long Island, New York. Cancer Causes Control 2009, 20(8):1509-1515.

21. Levi F, La Vecchia C, Gulie C, Negri E: Dietary factors and breast cancer risk in Vaud, Switzerland. Nutr Cancer 1993, 19(3):327-335.

22. Katsouyanni K, Trichopoulos D, Boyle P, Xirouchaki E, Trichopoulou A, Lisseos B, Vasilaros S, MacMahon B: Diet and breast cancer: a case-control study in Greece. Int J Cancer 1986, 38(6):815-820.

23. Ewertz M, Gill C: Dietary factors and breast-cancer risk in Denmark. Int J Cancer 1990, 46(5):779-784.

24. Simard A, Vobecky J, Vobecky JS: Nutrition and lifestyle factors in fibrocystic disease and cancer of the breast. Cancer Detect Prev 1990, 14(5):567-572.

25. Goodman MT, Nomura AM, Wilkens LR, Hankin J: The association of diet, obesity, and breast cancer in Hawaii. Cancer Epidemiol Biomarkers Prev 1992, 1(4):269-275.

26. Trichopoulou A, Katsouyanni K, Stuver S, Tzala L, Gnardellis C, Rimm E, Trichopoulos D: Consumption of olive oil and specific food groups in relation to breast cancer risk in Greece. J Natl Cancer Inst 1995, 87(2):110-116.

27. Nomura A, Henderson BE, Lee J: Breast cancer and diet among the Japanese in Hawaii. Am J Clin Nutr 1978, 31(11):2020-2025.

28. Gaard M, Tretli S, Loken EB: Dietary fat and the risk of breast cancer: a prospective study of 25,892 Norwegian women. Int J Cancer 1995, 63(1):13-17

29. Holmes MD, Liu S, Hankinson SE, Colditz GA, Hunter DJ, Willett WC: Dietary carbohydrates, fiber, and breast cancer risk. Am J Epidemiol 2004, 159(8):732-739.

30. Boyd NF, Byng JW, Jong RA, Fishell EK, Little LE, Miller AB, Lockwood GA, Tritchler DL, Yaffe MJ: Quantitative classification of mammographic densities and breast cancer risk: results from the Canadian national breast screening study. J Natl Cancer Inst 1995, 87(9):670-675.

31. Brisson J, Diorio C, Masse B: Wolfe's parenchymal pattern and percentage of the breast with mammographic densities: redundant or complementary classifications? Cancer Epidemiol Biomarkers Prev 2003, 12(8):728-732.

32. McCormack VA, dos Santos SI: Breast density and parenchymal patterns as markers of breast cancer risk: a meta-analysis. Cancer Epidemiol Biomarkers Prev 2006, 15(6):1159-1169.

33. Li T, Sun L, Miller N, Nicklee T, Woo J, Hulse-Smith L, Tsao MS, Khokha R, Martin L, Boyd N: The association of measured breast tissue characteristics with mammographic density and other risk factors for breast cancer. Cancer Epidemiol Biomarkers Prev 2005, 14(2):343-349.

34. Voon NS, Chelliah KK: Is there an influence of dietary habits on breast density as seen on digital mammograms? Asian Pac J Cancer Prev 2011, 12(8):1969-1972.

35. Masala G, Ambrogetti D, Assedi M, Giorgi D, Del Turco MR, Palli D: Dietary and lifestyle determinants of mammographic breast density. A longitudinal study in a Mediterranean population. Int J Cancer 2006, 118(7):1782-1789.

36. Diorio C, Pollak M, Byrne C, Masse B, Hebert-Croteau N, Yaffe M, Cote G, Berube S, Morin C, Brisson J: Insulin-like growth factor-I, IGF-binding protein-3, and mammographic breast density. Cancer Epidemiol Biomarkers Prev 2005, 14(5):1065-1073. 
37. Berube S, Diorio C, Brisson J: Multivitamin-multimineral supplement use and mammographic breast density. Am J Clin Nutr 2008, 87(5):1400-1404

38. London SJ, Colditz GA, Stampfer MJ, Willett WC, Rosner B, Speizer FE: Prospective study of relative weight, height, and risk of breast cancer. JAMA 1989, 262(20):2853-2858.

39. Wolf AM, Hunter DJ, Colditz GA, Manson JE, Stampfer MJ, Corsano KA, Rosner B, Kriska A, Willett WC: Reproducibility and validity of a self-administered physical activity questionnaire. Int J Epidemiol 1994, 23(5):991-999.

40. Caan BJ, Slattery ML, Potter J, Quesenberry CP Jr, Coates AO, Schaffer DM: Comparison of the Block and the Willett self-administered semiquantitative food frequency questionnaires with an interviewer-administered dietary history. Am J Epidemio/ 1998, 148(12):1137-1147.

41. Willett WC, Sampson L, Stampfer MJ, Rosner B, Bain C, Witschi J, Hennekens $\mathrm{CH}$, Speizer FE: Reproducibility and validity of a semiquantitative food frequency questionnaire. Am J Epidemiol 1985, 122(1):51-65.

42. Cuzick J, Warwick J, Pinney E, Warren RM, Duffy SW: Tamoxifen and breast density in women at increased risk of breast cancer. J Natl Cancer Inst 2004, 96(8):621-628.

43. Cuzick J, Forbes J, Edwards R, Baum M, Cawthorn S, Coates A, Hamed A, Howell A, Powles T: First results from the international breast cancer intervention study (IBIS-I): a randomised prevention trial. Lancet 2002 360(9336):817-824.

44. Fisher B, Costantino JP, Wickerham DL, Redmond CK, Kavanah M, Cronin WM, Vogel V, Robidoux A, Dimitrov N, Atkins J, Margolese RG, Runowicz CD, James JM, Ford LG, Wolmark N: Tamoxifen for prevention of breast cancer: report of the national surgical adjuvant breast and bowel project p-1 study. J Natl Cancer Inst 1998, 90(18):1371-1388.

45. Fung TT, Hu FB, Holmes MD, Rosner BA, Hunter DJ, Colditz GA, Willett WC: Dietary patterns and the risk of postmenopausal breast cancer. Int $J$ Cancer 2005, 116(1):116-121.

46. Nagata C, Matsubara T, Fujita H, Nagao Y, Shibuya C, Kashiki Y, Shimizu H: Associations of mammographic density with dietary factors in Japanese women. Cancer Epidemiol Biomarkers Prev 2005, 14(12):2877-2880.

47. Qureshi SA, Couto E, Hilsen M, Hofvind S, Wu AH, Ursin G: Mammographic density and intake of selected nutrients and vitamins in Norwegian women. Nutr Cancer 2011, 63(7):1011-1020.

48. Nordevang E, Azavedo E, Svane G, Nilsson B, Holm LE: Dietary habits and mammographic patterns in patients with breast cancer. Breast Cancer Res Treat 1993, 26(3):207-215.

49. Boyd NF, Stone J, Vogt KN, Connelly BS, Martin LJ, Minkin S: Dietary fat and breast cancer risk revisited: a meta-analysis of the published literature. Br J Cancer 2003, 89(9):1672-1685.

50. Smith-Warner SA, Spiegelman D, Adami HO, Beeson WL, van den Brandt PA, Folsom AR, Fraser GE, Freudenheim JL, Goldbohm RA, Graham S, Kushi LH, Miller AB, Rohan TE, Speizer FE, Toniolo P, Willett WC, Wolk A, ZeleniuchJacquotte A, Hunter DJ: Types of dietary fat and breast cancer: a pooled analysis of cohort studies. Int J Cancer 2001, 92(5):767-774.

51. Martin LJ, Li Q, Melnichouk O, Greenberg C, Minkin S, Hislop G, Boyd NF: A randomized trial of dietary intervention for breast cancer prevention. Cancer Res 2011, 71(1):123-133.

52. Martin LJ, Greenberg CV, Kriukov V, Minkin S, Jenkins DJ, Yaffe M, Hislop G, Boyd NF: Effect of a low-fat, high-carbohydrate dietary intervention on change in mammographic density over menopause. Breast Cancer Res Treat 2009, 113(1):163-172.

53. Bray GA: Energy and fructose from beverages sweetened with sugar or high-fructose corn syrup pose a health risk for some people. Adv Nutr 2013, 4(2):220-225

54. Ventura EE, Davis JN, Goran MI: Sugar content of popular sweetened beverages based on objective laboratory analysis: focus on fructose content. Obesity (Silver Spring) 2011, 19(4):868-874

55. Enzmann H, Ohlhauser D, Dettler T, Bannasch P: Enhancement of hepatocarcinogenesis in rats by dietary fructose. Carcinogenesis 1989 10(7):1247-1252

56. Stamp D, Zhang XM, Medline A, Bruce WR, Archer MC: Sucrose enhancement of the early steps of colon carcinogenesis in mice. Carcinogenesis 1993, 14(4):777-779.

57. Ludwig DS: Diet and development of the insulin resistance syndrome. Asia Pac J Clin Nutr 2003, 12 (Suppl):S4.
58. Kaaks R: Nutrition, hormones, and breast cancer: is insulin the missing link? Cancer Causes Control 1996, 7(6):605-625.

59. Kaaks R: [Plasma insulin, IGF-I and breast cancer]. Gynecol Obstet Fertil 2001, 29(3):185-191

60. Strange KS, Wilkinson D, Emerman JT: Mitogenic properties of insulin-like growth factors I and II, insulin-like growth factor binding protein-3 and epidermal growth factor on human breast epithelial cells in primary culture. Breast Cancer Res Treat 2002, 75(3):203-212.

61. Strange KS, Wilkinson D, Edin G, Emerman JT: Mitogenic properties of insulin-like growth factors I and II, insulin-like growth factor binding protein-3 and epidermal growth factor on human breast stromal cells in primary culture. Breast Cancer Res Treat 2004, 84(2):77-84

62. Pollak MN: Endocrine effects of IGF-I on normal and transformed breast epithelial cells: potential relevance to strategies for breast cancer treatment and prevention. Breast Cancer Res Treat 1998, 47(3):209-217.

63. Wang B, Bobe G, LaPres JJ, Bourquin LD: High sucrose diets promote intestinal epithelial cell proliferation and tumorigenesis in APC(Min) mice by increasing insulin and IGF-I levels. Nutr Cancer 2009, 61(1):81-93.

64. Krajcik RA, Borofsky ND, Massardo S, Orentreich N: Insulin-like growth factor I (IGF-I), IGF-binding proteins, and breast cancer. Cancer Epidemiol Biomarkers Prev 2002, 11(12):1566-1573.

65. Toniolo P, Bruning PF, Akhmedkhanov A, Bonfrer JM, Koenig KL, Lukanova A, Shore RE, Zeleniuch-Jacquotte A: Serum insulin-like growth factor-I and breast cancer. Int J Cancer 2000, 88(5):828-832.

66. Renehan AG, Zwahlen M, Minder C, O'Dwyer ST, Shalet SM, Egger M: Insulin-like growth factor (IGF)-I, IGF binding protein-3, and cancer risk: systematic review and meta-regression analysis. Lancet 2004, 363(9418):1346-1353.

67. Byrne C, Colditz GA, Willett WC, Speizer FE, Pollak M, Hankinson SE: Plasma insulin-like growth factor (IGF) I, IGF-binding protein 3, and mammographic density. Cancer Res 2000, 60(14):3744-3748.

68. Boyd NF, Stone J, Martin LJ, Jong R, Fishell E, Yaffe M, Hammond G, Minkin S: The association of breast mitogens with mammographic densities. Br J Cancer 2002, 87(8):876-882.

69. Gunter MJ, Hoover DR, Yu H, Wassertheil-Smoller S, Rohan TE, Manson JE, Li J, Ho GY, Xue X, Anderson GL, Kaplan RC, Harris TG, Howard BV, WylieRosett J, Burk RD, Strickler HD: Insulin, insulin-like growth factor-I, and risk of breast cancer in postmenopausal women. J Natl Cancer Inst 2009, 101(1):48-60.

70. Wolin KY, Colangelo LA, Chiu BC, Ainsworth B, Chatterton R, Gapstur SM: Associations of physical activity, sedentary time, and insulin with percent breast density in Hispanic women. J Womens Health (Larchmt) 2007, 16(7):1004-1011

71. Diorio C, Pollak M, Byrne C, Masse B, Hebert-Croteau N, Yaffe M, Cote G, Berube S, Brisson J: Levels of C-peptide and mammographic breast density. Cancer Epidemiol Biomarkers Prev 2005, 14(11 Pt 1):2661-2664.

72. Garcia-Contreras F, Paniagua R, Avila-Diaz M, Cabrera-Munoz L, MartinezMuniz I, Foyo-Niembro E, Amato D: Cola beverage consumption induces bone mineralization reduction in ovariectomized rats. Arch Med Res 2000, 31(4):360-365.

73. Olson ML, Maalouf NM, Oden JD, White PC, Hutchison MR: Vitamin D deficiency in obese children and its relationship to glucose homeostasis. J Clin Endocrinol Metab 2012, 97(1):279-285.

74. Welsh J: Cellular and molecular effects of vitamin D on carcinogenesis. Arch Biochem Biophys 2012, 523(1):107-114.

75. Brisson J, Berube S, Diorio C, Sinotte M, Pollak M, Masse B: Synchronized seasonal variations of mammographic breast density and plasma 25-hydroxyvitamin d. Cancer Epidemiol Biomarkers Prev 2007, 16(5):929-933.

76. Mohr SB, Gorham ED, Alcaraz JE, Kane CJ, Macera CA, Parsons JK, Wingard DL, Garland CF: Serum 25-hydroxyvitamin D and prevention of breast cancer: pooled analysis. Anticancer Res 2011, 31(9):2939-2948.

77. Chen P, Hu P, Xie D, Qin Y, Wang F, Wang H: Meta-analysis of vitamin D, calcium and the prevention of breast cancer. Breast Cancer Res Treat 2010, 121(2):469-477.

doi:10.1186/1471-2458-14-554

Cite this article as: Duchaine et al:: Consumption of sweet foods and mammographic breast density: a cross-sectional study. BMC Public Health 2014 14:554. 